\title{
Villes (gouache et encre)
}

\section{Christophe Didier}

\section{(2) OpenEdition}

\section{Journals}

Édition électronique

URL : https://journals.openedition.org/rbnu/2890

DOI : $10.4000 /$ rbnu. 2890

ISSN : 2679-6104

\section{Éditeur}

Bibliothèque nationale et universitaire de Strasbourg

\section{Édition imprimée}

Date de publication : 1 mai 2012

Pagination : 84-95

ISSN : 2109-2761

\section{Référence électronique}

Christophe Didier, «Villes (gouache et encre) », La Revue de la BNU [En ligne], 5 | 2012, mis en ligne le 01 mai 2012, consulté le 25 août 2021. URL : http://journals.openedition.org/rbnu/2890 ; DOl : https:// doi.org/10.4000/rbnu.2890

Ce document a été généré automatiquement le 25 août 2021.

\section{(c) (i) (2) (2)}

La Revue de la BNU est mise à disposition selon les termes de la Licence Creative Commons Attribution - Pas d'Utilisation Commerciale - Partage dans les Mêmes Conditions 4.0 International. 


\section{Villes (gouache et encre)}

\section{Christophe Didier}

$1 \quad$ Les villes n'existent pas. il existe ma ville, ta ville, nos villes...

2 Mes villes - lettres, mots, lignes et couleurs - restituent par touches éparses la somme des impressions fugitives qui finissent par dire la vérité d'un lieu.

Köln II, $2008(66 \times 114 \mathrm{~cm})$

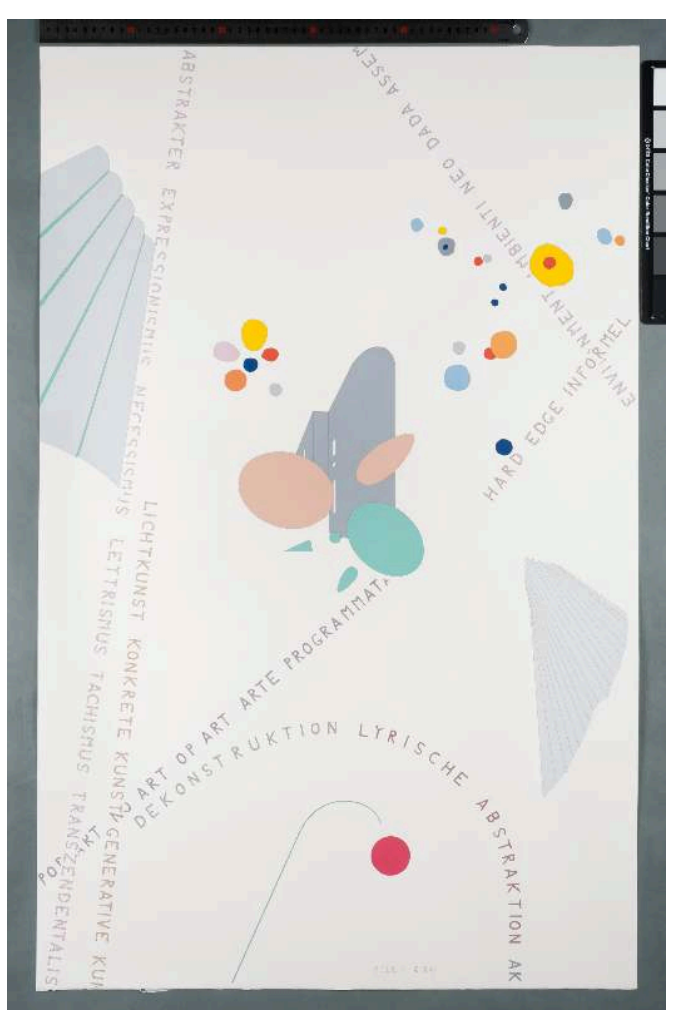

Cliché JPR-Bnu CC-BY-NC-SA 
Düsseldorf I, $2005(70 \times 114 \mathrm{~cm})$

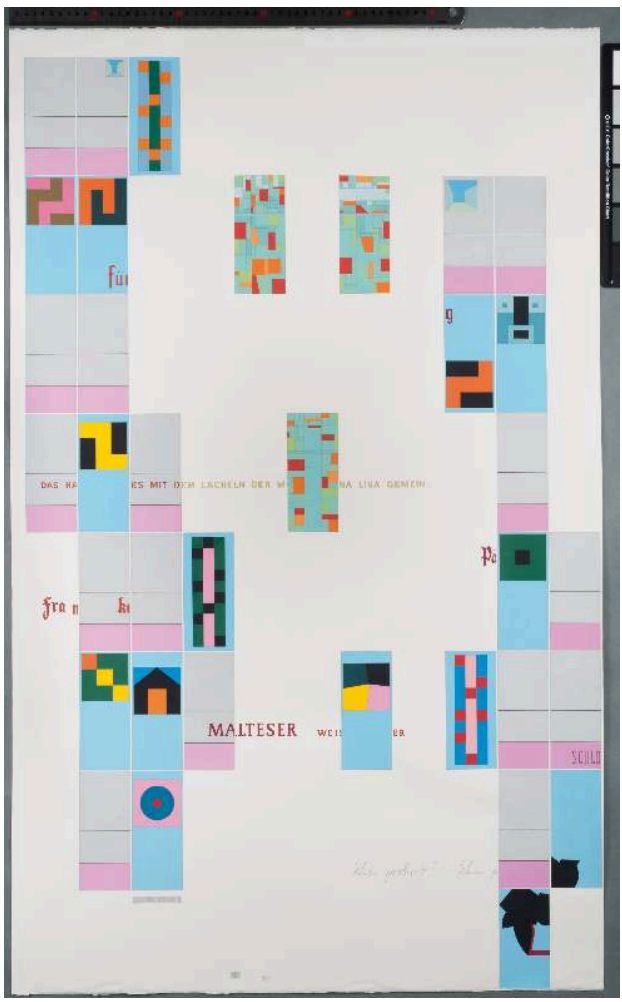

Cliché JPR-Bnu CC-BY-NC-SA

Kunst ist Bewegung, $2007(50 \times 114 \mathrm{~cm})$

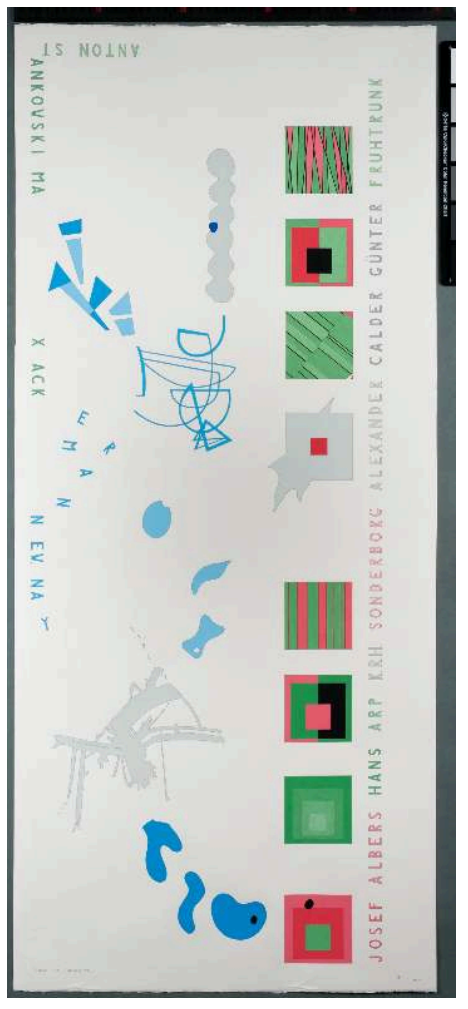

Cliché JPR-Bnu CC-BY-NC-SA 
Ortenau, $2009(65 \times 114 \mathrm{~cm})$

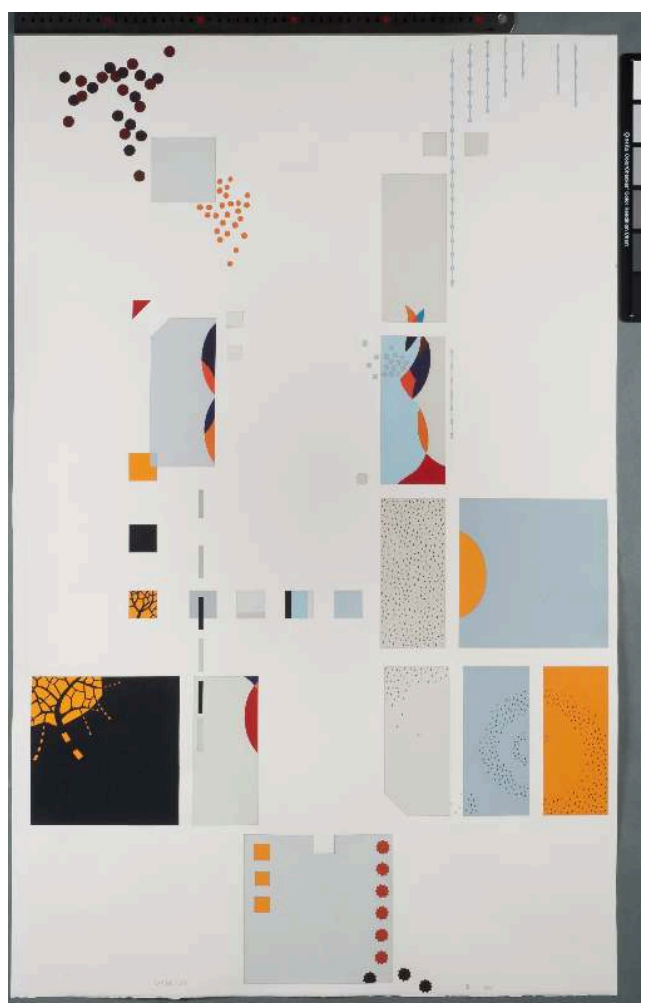

Cliché JPR-Bnu CC-BY-NC-SA

Köln III, 2008-2009 (66 x 114 cm)

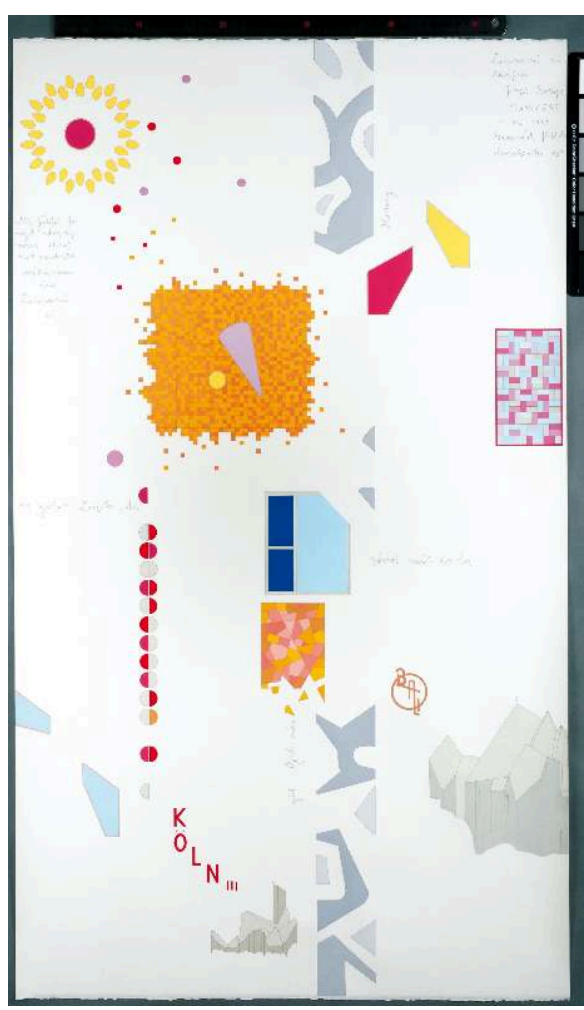

Cliché JPR-Bnu CC-BY-NC-SA 
Stuttgart II, 2004-2005 (58 x $77 \mathrm{~cm})$

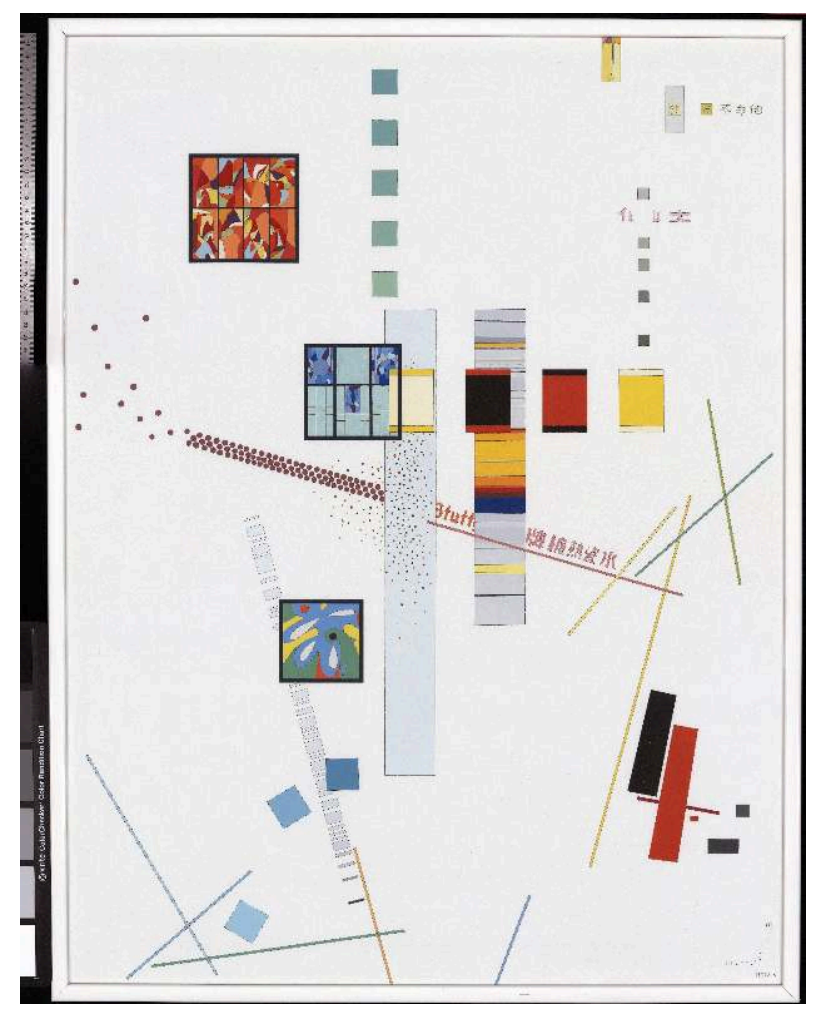

Cliché JPR-Bnu CC-BY-NC-SA

\section{AUTEUR}

\section{CHRISTOPHE DIDIER}

Conservateur, adjoint de l'administrateur de la BNU 